\title{
ERRATUM
}

\section{Calculation of pigment transition energies in the FMO protein}

\section{From simplicity to complexity and back}

\author{
Julia Adolphs · Frank Müh • Mohamed El-Amine Madjet • \\ Thomas Renger
}

Published online: 31 October 2007

(C) Springer Science+Business Media B.V. 2007

\section{Erratum to: Photosynth Res}

\section{DOI 10.1007/s11120-007-9248-z}

The legend in the top, left-hand panel in Fig. 6 of the original article was incorrect. The legend for the green line should read 'Fit' (see corrected Fig. 6 on this page).

The online version of the original article can be found under doi:10.1007/s11120-007-9248-z.

J. Adolphs · F. Müh · M. E.-A. Madjet · T. Renger ( $\square)$

Institut für Chemie und Biochemie, Freie Universität Berlin,

Takustrasse 6, Berlin 14195, Germany

e-mail: rth@chemie.fu-berlin.de

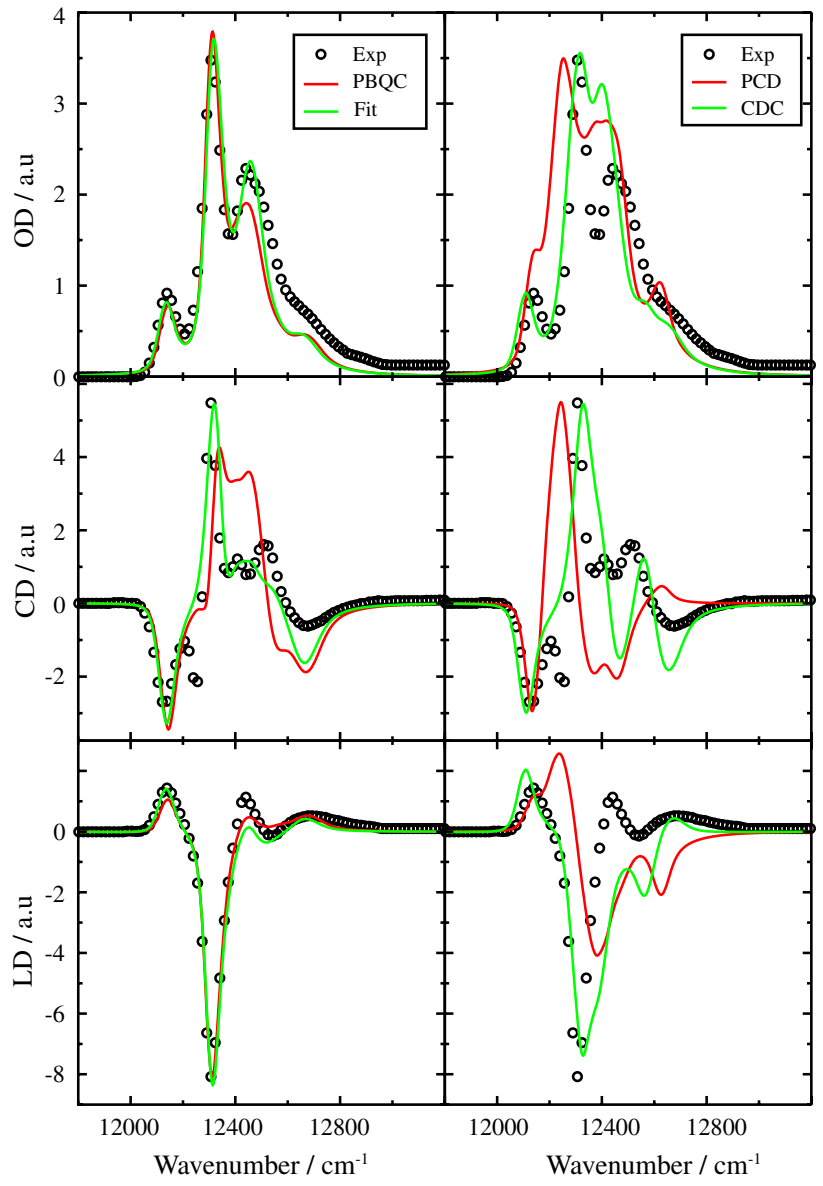

Fig. 6 Comparison of $4 \mathrm{~K}$ absorption (OD), circular dichroism (CD) and linear dichroism (LD) experimental data (Wendling et al. 2002) (circles) with calculations, using the site energies obtained with different methods (Table 2) and a point dipole approximation (Eq. 10, $f=0.8$ ) 